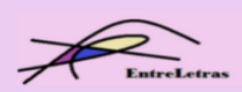

REVISTA ENTRELETRAS (ARAGUAÍNA), V. 12, N. 3, SET./DEZ. 2021 (ISSN 2179-3948 - ONLINE)

\title{
AUTOFAGIA, ENREDO E DESENREDO EM A RAINHA DOS CÁRCERES DA GRÉCIA, DE OSMAN LINS
}

\section{AUTOFAGY, PLOT AND UNRAVELING IN A RAINHA DOS CÁRCERES DA GRÉCIA, BY OSMAN LINS}

\author{
DOI 10.20873/uft2179-3948.2021v12n3p396-409
}

\section{Leonardo Brandão de Oliveira Amaral ${ }^{1}$}

\begin{abstract}
Resumo: Este trabalho, fundamentado nos conceitos propostos por Mikhail Bakhtin, empreende uma leitura de $A$ rainha dos cárceres da Grécia, de Osman Lins, com o objetivo de demonstrar sua construção arquitetônica. Para tal, analisam-se as construções composicionais que realizam a forma arquitetônica, elencando como fundamentais à sua leitura crítica: a teorização estética realizada pela própria narrativa; a configuração do enredo em uma forma dissimuladora de sua literariedade e o processo de desenredo, operado e conceituado pelo próprio narrador. Nota-se que a obra se realiza/estrutura arquitetonicamente como uma autofagia crítica, um romance que tenta explicar-se, completar-se em todos os seus momentos.
\end{abstract}

Palavras-chave: Arquitetônica; Teoria literária; Mikhail Bakhtin; Osman Lins.

Abstract: This work, based upon the concepts proposed by Mikhail Bakhtin, develops a reading of A rainha dos cárceres de Grécia, by Osman Lins, with the objective of demonstrating its architectural construction. To this end, the compositional constructions that make up the architectural form are analyzed, listing as fundamental to its critical reading: the aesthetic theorizing, carried out by the narrative itself; the setting of the plot in a way that conceals its literariness; and the unraveling process, operated and conceptualized by the narrator himself. It is noted that the work is architecturally realized/structured as a critical autophagy, a novel that tries to explain itself, to complete itself in all of its moments.

Keywords: Architectonics; Literary theory; Mikhail Bakhtin; Osman Lins.

\section{Introdução}

A criação literária, em sentido amplo, é notável pela sua complexidade. A atividade esteticamente criativa e de caráter dialógico que a funda e permeia multiplica o número de possibilidades de sentido e cifra o seu próprio processo criador. Um dos problemas dos estudos que tomam o objeto estético como parte ou totalidade dos seus corpora, em geral, é compreender sua natureza em complexidade, plenitude e originalidade, aspectos que Mikhail

\footnotetext{
${ }^{1}$ Mestrando em Letras pela Universidade Estadual Paulista "Júlio de Mesquita Filho" - Ibilce/Unesp. Bolsista Capes. E-mail: leonardobrandaooa@gmail.com ORCID: https://orcid.org/0000-0002-4473-3236
} 


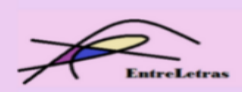

REVISTA ENTRELETRAS (ARAGUAÍNA), V. 12, N. 3, SET./DEZ. 2021 (ISSN 2179-3948 - ONLINE)

Bakhtin (2014) aponta como importantes para uma ciência sobre domínios da criação cultural. Decifrar, portanto, a singularidade, as tradições e as relações que enredam o processo e as obras é etapa primária e necessária para qualquer estudo poético, ou que faça uso do objeto deste.

Diante de tal complexidade, o estudioso da literatura se debruça sobre o problema da estética literária. No seu processo, esquadrinha não só as relações da literatura com a sociedade, a cultura e a história, como a própria complexidade do objeto. Supera a criação poética, da mesma forma que Bakhtin (2014) considera que o objeto estético supera o material ${ }^{2}$. Misturase a ela, torna-se um com a obra, na medida em que circunscreve seu próprio discurso, sua atuação como autor-contemplador, para utilizar o termo como Bakhtin (2003), e seu próprio ato responsivo, sua compreensão e resposta, no plano discursivo do objeto estético.

Aos estudos que empreendem tal objetivo não faltam variações. A crítica literária, focando em especificidades da produção de autores e de obras, explora o individual em relação a parâmetros gerais ou alheios ao objeto primário, como no caso da literatura comparada. Em oposição, a teoria literária busca as generalidades e tradições, objetivando a compreensão de questões recorrentes, alinhadas a obras, autores, períodos e tradições. Os trabalhos de críticos e teóricos elucidam e ampliam o conjunto ideológico que participa do fundo dialógico da criação literária, alimentando as criações posteriores e também, se levarmos em conta as palavras de Jorge Luís Borges (1974), as anteriores, com material para sua atuação. Ao mesmo tempo singular e exemplar espécime do diálogo entre estudos literários e criação literária, é $A$ rainha dos cárceres da Grécia (1976), de Osman Lins.

Nesse romance, o conhecimento crítico da criação literária assume protagonismo. $\mathrm{O}$ narrador, um homem que escreve em seu diário um ensaio crítico sobre o romance não publicado da sua falecida amante, apesar de não ser profissionalmente um homem de letras, demonstra profundo interesse em compreender a obra, como um tributo à amada, uma prática de escrita e, o que fica evidente ao longo da sua tarefa, uma busca pela própria identidade através da reverenciada criatura da falecida. A complexidade da obra, em sua forma e conteúdo, é facilmente perceptível. Seus recursos expressivos fogem dos tradicionais, misturando o epistolar e o monólogo interior à crítica e à teoria literária, para apenas mencionar os mais recorrentes. Na sua totalidade, o texto problematiza os três elementos de natureza social e

\footnotetext{
${ }^{2}$ A respeito disso, cabe elucidar que a superação do material, para Bakhtin (2014), ocorre na medida em que a forma artística supera a natureza extraestética do material, que, no caso literário, é a determinação linguística. O artista, assim, libera a determinação material para formalizar, artisticamente, um conteúdo. Em razão disso, Bakhtin vê a realização do objeto estético como a transformação do material num "[...] todo arquitetônico de um evento esteticamente acabado..." (2014, p. 51), o que transforma as ligações verbais, na literatura, em relações arquitetônicas extraverbais.
} 


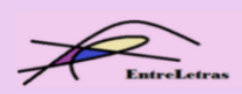

REVISTA ENTRELETRAS (ARAGUAÍNA), V. 12, N. 3, SET./DEZ. 2021 (ISSN 2179-3948 - ONLINE)

psíquica, como definidos por Candido, que "[...] se manifestam historicamente e fazem da literatura aspecto orgânico da civilização.” (CANDIDO, 2017, p. 25). Estes fatores - os conjuntos de produtores, os receptores e o mecanismo transmissor - são, todos, partes, e problemas, estruturantes da obra de Lins. Em A rainha dos cárceres da Grécia, eles se configuram no problema da posição social de Julia Marquezim Enone, negativamente considerada, ou mesmo desconsiderada, como autora (em certos momentos, até pelo próprio narrador); na não publicação póstuma do seu romance, em grande parte ocasionada pelo receio da recepção que a obra poderia ter; e nas esferas da sociedade, em suas relações tradicionalistas, que não comportam tanto a autora quanto a sua protagonista. A obra de Julia Marquezim Enone não faz parte da literatura como sistema, mencionada por Candido (2017), ela é rejeitada pela imprensa, negada sua publicação pela família da autora e o único contato que seu trabalho realmente tem com o público leitor amplo é através da crítica literária do seu amante que, como já foi notado em Martins (2010), parece, na maior parte do texto, mais interessado com seu reflexo do que com a autora ou a obra que estuda. Assim, a obra de Lins, ao mesmo tempo que se institui como objeto estético, propõe postulações sobre o próprio gênero no qual se inscreve, especulando sobre o conteúdo e a forma do romance.

Os campos discursivos, portanto, em que A rainha dos cárceres da Grécia habita incluem, assim, as elaborações de teorias estéticas. Subjacente à intriga central - a experiência do narrador com a exploração do mundo e a memória da amada -, são desenvolvidos hipóteses e argumentos sobre o fazer literário. Se pensarmos como Leyla Perrone-Moisés (2013), em sua leitura da discussão de Tzvetan Todorov (2013) e do estruturalismo, na qual considera que os modelos teóricos servem para “[...] através deles, apreender [sic] a dar conta da originalidade de cada obra [...]" (PERRONE-MOISÉS, 2013, p. 14), a obra de Lins explicita um caminho interpretativo para ela mesma.

Tem-se, assim, o caso de uma bivocalidade da palavra. Ela é dirigida explicitamente a um objeto: a obra de Julia Marquezim Enone. Contudo, implicitamente, elucida questões referentes à própria atividade criativa do narrador. O romance de Lins coloca-se como crítico de si mesmo, joga com a inconclusibilidade natural das formas estéticas, incorporando à sua composição o estético, o crítico e o extraliterário, em uma tentativa de completar a si mesma.

Para compreender esse processo, propõe-se uma leitura estética, partindo de tais elementos estruturantes da sua forma. Quatro processos serão destacados: a especulação teórica, que coloca em relevo o contraste entre o narrador e o autor; a configuração da intriga, que inclui a relação problemática entre o narrador e Julia Marquezim Enone; o desenredamento, 


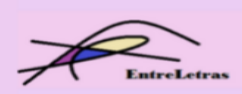

REVISTA ENTRELETRAS (ARAGUAÍNA), V. 12, N. 3, SET./DEZ. 2021 (ISSN 2179-3948 - ONLINE)

processo associado à bivocalidade da palavra, pelo qual o narrador provê explicações para o romance que estuda e o que ele próprio escreve; e a problematização da cisão entre estético e extraestético, que caracteriza uma constante quebra de níveis, contaminação mútua desses dois mundos, tanto na teoria especulada (pelo narrador) quanto na realidade representada (pelo romance). Pretende-se, no todo deste trabalho, elaborar uma compreensão acurada da forma arquitetônica da obra, como definida por Bakhtin (2014).

\section{Teoria, enredo e desenredo: três momentos do texto}

Quatro processos destacam-se na construção composicional do romance de Osman Lins. O primeiro, como mencionado, é decorrente do desenvolvimento de uma teoria e crítica literárias internas à própria prosa. Por meio dele, dois agentes adquirem protagonismo: o narrador e o autor.

O narrador dialoga, em sua deliberação, com pelo menos três interlocutores explícitos: a comunidade de letras, com a qual discute e contesta definições; os possíveis leitores do seu "ensaio", que aparecem mais frequentemente e diretamente mencionados; e a própria Julia Marquezim Enone, seja como pessoa ou autora-criadora do romance analisado. A cada um deles, voltam-se as várias facetas da construção composicional. O cuidado com a discussão teórica e crítica indicia a preocupação com o olhar do estudioso da literatura, capaz de julgar os erros metodológicos da análise. A comunicação com tal grupo interlocutor é explicitamente estruturante do texto. Logo no quinto registro do seu diário, há o relato de uma conversa com um acadêmico, “[...] A.B., docente na Pontifícia Universidade Católica [...]” (LINS, 1976, p. 3), com o qual suas ideias divergem, uma vez que o confidente considera negativa a intimidade com a autora para a análise do narrador. Esta posição é rebatida, em um registro seguinte, sob a afirmação de que mesmo uma “[...] simples carta pode ser mais bem compreendida se confrontada com outras - anteriores e talvez até ulteriores - de quem a enviou." (LINS, 1976, p. 5) Vê-se, no trecho, uma das primeiras postulações diretas de teoria literária dentro do romance. O efeito especial dela, no entanto, não se dá apenas pela sua abordagem, mas pela discussão à qual se conecta. Após o trecho citado, a fim de defender a tese, lê-se:

É o que nos afirma, a seu modo, um argentino que entende dessas coisas, Jorge Luís Borges, no conto em que Ménard, palavra por palavra, escreve o romance de Cervantes. O estilo do Quixote, natural no seu primeiro autor, em Pierre Ménard fazse arcaizante. (LINS, 1976, p. 5, grifo do autor) 


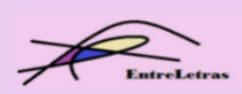

REVISTA ENTRELETRAS (ARAGUAÍNA), V. 12, N. 3, SET./DEZ. 2021 (ISSN 2179-3948 - ONLINE)

A inclusão de Pierre Ménard, autor del Quijote (BORGES, 1997) e Borges é significativa. Por um lado, inclui, diretamente, um dos estudiosos que faria parte de grupos interlocutores. Por outro lado, as duas obras, às suas maneiras, mas com grande semelhança, ameaçam as fronteiras do gênero em que se inserem. Ambas elegem como objetos temáticos a criação literária e seus autores. As semelhanças aparecem, ainda, na escolha da forma, uma vez que Borges também se afasta de modelos tradicionais, escrevendo uma ficção que mais se aproxima do "[...] gênero ensaístico por se caracterizar como texto que enfoca uma reflexão mais intelectualizada sobre um determinado tema, a qual se desenvolve baseada em um exemplo específico, que neste caso é a história de Pierre Ménard.” (NUNES, 2007, p. 71).

A rainha dos cárceres da Grécia, por sua vez, não se põe tão à margem da forma ficcional quanto o conto de Borges. O segundo processo, dos que mencionamos no início dessa seção, e que se destacam na construção composicional, é a configuração de um enredo que perpassa toda a obra: a relação entre o narrador e Julia Marquezim Enone, tanto como autora quanto como pessoa. Os aspectos referentes às partes dominadas por tal relação, mesmo nos momentos teorizantes, são, essencialmente, da prosa artística. Há trechos, como o relato de uma conversa entre o narrador e a sua sobrinha, Alcmena, a respeito do aniversário da já falecida autora, em que o texto explicitamente abandona a forma anterior (LINS, 1976, p. 86), cedendo espaço à narrativa diretamente implicada.

A construção do enredo, conferindo ao artístico o que se propõe, a princípio, como ensaio literário, configura o todo arquitetônico do romance de Osman Lins. Os limites entre o mundo estético, o acadêmico e o pessoal são delimitados com clareza, conferindo ao texto sua singularidade. Nela, um narrador pessoalizado busca, através do cognoscível, compreender a si e à falecida amada pela análise da sua obra estética.

No processo da sua compreensão - de Julia Marquezim Enone e de si próprio -, segue a via da análise literária, em detrimento de outros estudos, como o sociológico e o psicológico. A escolha, portanto, não é arbitrária, considerando que a forma adotada passa pelo julgo de uma consciência criativa, o autor-criador do romance, que chamaremos pelo nome do autor-pessoa, Osman Lins, mas não deve se confundir com ele, como bem explicita Bakhtin (2003). Utilizando como forma composicional uma narrativa que toma como principal base filosófica o estudo estético, este se torna vetor interno do todo arquitetônico da obra. Assim, entender como o narrador tenta desenredar a obra da sua amada não é um processo importante apenas para os estudos teóricos. Esta exigência é decisiva para compreender o próprio enredo da obra, que especula, explicitamente, sobre outra, o romance de Julia Marquezim Enone, também 


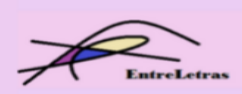

REVISTA ENTRELETRAS (ARAGUAÍNA), V. 12, N. 3, SET./DEZ. 2021 (ISSN 2179-3948 - ONLINE)

intitulado, não por acaso, A rainha dos cárceres da Grécia. O diário-ensaio, por sua vez, também reflete, implicitamente, sobre si mesmo, uma vez que, como pretendeu-se ter demonstrado, é ele próprio um romance, dotado de todas as características discursivas do gênero, como definidas por Bakhtin (2014). O texto teoriza a análise literária recorrendo à figura do "desenredamento", que se destaca como o terceiro processo privilegiado.

A respeito dos aspectos da obra de arte, seja do romance ou de outra forma poética, específicos de certo objeto estético ou assemelháveis entre eles, a discussão do narrador reflete posicionamentos que elucidam problemas do seu próprio enredo, relevantes à sua compreensão. O primeiro deles é a relação ética entre a escrita do narrador e o objeto do seu "ensaio". Em razão da não publicação do texto, ele levanta a questão: seria a obra literária um bem coletivo?

A sua resposta é direta: “A obra, mesmo embrionária, concerne ao ente coletivo - nós de cuja substância ela se forma." (LINS, 1976, p. 2). Tal proposição, recorrente e associada principalmente a estudos que relacionam o objeto estético às influências da realidade, seja em qual sentido for, é especialmente significativa para a conclusibilidade do livro. Adiante, quando estuda as personagens, o narrador percebe a presença de indivíduos ilustres da história dentro da narrativa, sejam eles heróis nacionais que passam a ser apenas membros das máquinas burocráticas do governo ou escritores famosos que estão internados em hospitais psiquiátricos. Pessoas reais, individualmente ou agrupados, são tornados, assim, partes estruturantes da narrativa: Machado de Assis é representado de "[...] pele escura e rosto pintado de alvaiade, de chapéu alto e luvas, piscando com malícia.” (LINS, 1976, p. 181), José de Alencar “[...] acredita ser proprietário de um enfermeiro negro, enfeita-se com penas de arara e tudo dissimula sob frases pomposas...” (LINS, 1976, p. 181) e Gregório de Matos, que grita e protesta contra tudo no hospício, é um “[...] ancião inquieto, empertigado, olhos pequenos e cínicos, nariz de quem fareja o mundo, a boca um lanho oblíquo e corrosivo...” (LINS, 1976, p. 181-182). Essa relação ainda adquire reciprocidade, porque não é apenas no coletivo em que a obra literária se forma; o próprio coletivo se compõe, em certa medida, da obra.

O amante, enquanto narrador e crítico literário, consciente da relação entre o extraliterário e a estruturação da obra, procura marcas de si no texto. Nessa busca, naquilo que é a mais relevante memória e contato com sua amada falecida, sua única herança, explora as personagens e o enredo, tentando decifrar-se, buscando seu reflexo nos olhos dela. No entanto, uma consideração desse movimento de enredo e desenredo a que se propõe o romance explicita a perspectiva reflexiva do narrador e do autor-criador, cuja obra, ao eleger, aparentemente, um segundo texto como objeto, na verdade, volta-se para si mesma. 


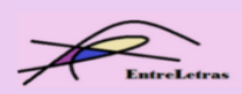

REVISTA ENTRELETRAS (ARAGUAÍNA), V. 12, N. 3, SET./DEZ. 2021 (ISSN 2179-3948 - ONLINE)

Esse mecanismo merece uma análise aprofundada. A respeito da estruturação dos eventos da narrativa, o narrador nota um comportamento dissimulador da romancista. Essa atitude, em que a narradora "[...] empenha-se em dissimular os seus achados." (LINS, 1976, p. 9) seria, na hipótese dele, fundamental para a compreensão adequada do livro. No relato do dia seguinte, ele critica o procedimento de resumir livros, o que seria uma prática "[...] superficial que difunde e reanima a ideia corrente segundo a qual a história é o romance, não um de seus aspectos, dos que menos ilustram a arte de narrar.” (LINS, 1976, p. 10, grifo do autor). Uma postulação assim, que muito se parece com a distinção entre forma e conteúdo e o método segundo os quais Bakhtin (2014) efetua a contraposição de tais constituintes da obra estética, à primeira vista, assemelha-se apenas a uma teorização sobre a natureza da criação literária. No entanto, associando tal postulação ao romance de Lins, toma aspectos mais definíveis. Como seria um resumo de A rainha dos cárceres da Grécia?

Diante de uma descrição que desconsiderasse a forma da narrativa, a confusão sobre o gênero literário da obra de Osman Lins seria refeita. O conteúdo, à primeira vista, abstraindo sua relação com a forma, novamente nos apoiando em Bakhtin (2014), é antes o de um diário ou ensaio crítico do que o de um romance. É a formalização do conteúdo que o torna, propriamente, uma obra literária. A atitude dissimuladora, portanto, não é exclusiva da narradora de Julia Marquezim Enone, mas também do narrador de Osman Lins: ambos cifram o conteúdo através da forma.

O narrador percebe a relação complexa, entre o autor e o leitor, que funda esse problema, o caráter dialógico do objeto estético. Sua opinião, sobre isso, é bem assertiva, considerando absurda a ideia de um “[...] narrador que tudo sabe!” (LINS, 1976, p. 64). Ele expressa consciência da necessidade de reconhecer a "visão da narrativa", de notar que narrar “[...] supõe testemunhar - real ou falsamente - e como fazê-lo sem colocar-se num determinado ponto ou em vários." (LINS, 1976, p. 65, grifo do autor), isto é, da necessária entonação expressiva e da presença do autor-criador em todo objeto estético. Mais uma vez, implicitamente somos levados a ver a face oculta, mas sempre presente, do romance: uma obra que elenca um tema e desenvolve complementarmente outro.

A dissimulação de um ponto de vista explícito, por parte do narrador, diante da romancista, revela-se sempre em um movimento falseado. Dirige-se para fora, quando na verdade também aponta para dentro. Ele considera que

Declina o romance atual do que foi ponto de honra no passado e respondeu por tantas dissimulações mais ou menos ingênuas (confissões de personagens, manuscritos encontrados pelo escritor), com o fim de legitimar a história e as 'recordações' do 


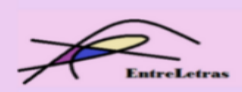

REVISTA ENTRELETRAS (ARAGUAÍNA), V. 12, N. 3, SET./DEZ. 2021 (ISSN 2179-3948 - ONLINE)

leitor, pronto a restaurar, solicitado pelo texto (uma hipnose?), segmentos insuspeitos do mundo. $\mathrm{O}$ escritor ostenta os seus artifícios, prestigiados na hierarquia nova do gênero. Impõe, com isto, sua presença e parece dizer a cada um de nós: 'Não acreditais em mim? Melhor. Isto é fala e artifício.' (LINS, 1976, p. 63).

O que é o romance de Osman Lins, senão fala e artifício? Diante dos olhos do leitor, ele coloca um narrador que dissimula um gênero, enquanto claramente expõe, por meio das suas próprias teorizações, o caráter literário da obra. Diz ter como objetivo estudar o trabalho da amada, mas especula mais sobre si do que sobre ela. Privilegia, acima de tudo, a fala autorreflexiva, sempre deixando clara a sua posição ativa no processo criador da obra. Externa perguntas, como: “[...] quanto ao 'meu’ livro, qual será o seu assunto?” (LINS, 1976, p. 59), ao passo que já dispôs, diante do leitor, a resposta delas, falseando não a resposta, mas as perguntas.

\section{3 Às margens entre o estético e o extraestético}

Espera-se, a esta altura, estar explicitado e elucidado o problema da tendência autorreflexiva do movimento de desenredo. Ele é suportado pelo processo de enredo de uma narrativa que a princípio dissimula seu gênero e sua natureza estética e pelo processo de teorização de um gênero que lhe seria alheio. Feito isso, falta relacionar essa tendência com o fio condutor geral da obra, a fim de compreendê-la como um todo arquitetônico.

Para tal, o quarto processo falta ser explicitado, assim como a relação que o texto mantém com um componente do fundo dialógico que teve papel secundário, até então: a presença do leitor e do seu mundo diegético. Os dois elementos que guiam o fim da leitura aqui proposta são correlatos. Ao passo que a narrativa constrói um enredo que tematiza a natureza da criação artística, ela prioriza uma relação imprescindível a todo objeto estético, a conexão entre o estético e o extraestético, ou, nos referindo às postulações de Bakhtin (2014), a sua participação na unidade da cultura.

A relação entre esses dois mundos é natural e irremediável. O caráter dialógico do discurso artístico, como já mencionado, conecta, por meio do estético, o mundo da vida a si mesmo. O leitor, na literatura, tem acesso ao produto de uma consciência criativa do escritor, que individualiza e isola o mundo estético da obra, afasta-o dos outros, como aponta Bakhtin (2014).

Toda análise que, portanto, pretenda estudar o objeto estético passa por dois processos correlatos: o estético e o dialógico. O resultado deve ser uma compreensão que considere as 


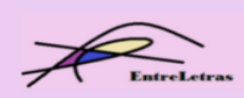

REVISTA ENTRELETRAS (ARAGUAÍNA), V. 12, N. 3, SET./DEZ. 2021 (ISSN 2179-3948 - ONLINE)

generalidades e especificidades do estético. Por um lado, naquilo que concerne à sua integração no todo da cultura. Por outro, no que se refere, especialmente, à própria forma artística à qual é relacionado e à natureza dialógica do objeto literário, que considera o mundo extraestético como parâmetro ao qual o mundo estético é inevitavelmente comparado ou associado.

A pertinência da relação com o real é ponto fundamental para toda uma variedade de estudos literários. As postulações de Candido (1980) explicitam e exemplificam essa perspectiva, uma vez que encontram na realidade fatores fundamentais para a compreensão do fenômeno literário. Para ele, o objeto estético só pode ser compreendido

[...] fundindo texto e contexto numa interpretação dialética íntegra, em que tanto o velho ponto de vista que explicava pelos fatores externos, quanto o outro, norteado pela convicção de que a estrutura é virtualmente independente, se combinam como momentos necessários do processo interpretativo. (CANDIDO, 1980, p. 4)

O social, externo, deve ser considerado como estrutura da obra, portanto, torna-se interno. A análise literária, para Candido (1980), deve ser capaz de compreender essa interdependência sem exacerbar a função de cada um dos seus elementos.

A pertinência do real para o estético, no entanto, não se esgota na relação dialógica entre os dois mundos, efetuada pela ação dos agentes do discurso. A arte é, em certa medida, ela mesma social e ocupa espaço no mundo da vida, apesar de isolar-se através da forma. Mas qual o grau e a natureza dessa relação, uma vez que, como se discutiu, a obra estética se constitui em limites, embora conectada com o todo da realidade e dos mundos que a constituem?

Como foi posto, a arte se estabelece em uma relação dialógica com a realidade. Se, por um lado, isola-se dela, por outro, depende da realidade para ser constituída e alcançar seu acabamento semântico. Candido (1980) estabelece essa relação em dois sentidos. No primeiro, a arte depende do meio, o qual se expressa na obra em diferentes graus de sublimação. No segundo, “[...] produz sobre os indivíduos um efeito prático, modificando a sua conduta e concepção do mundo, ou reforçando neles o sentimento dos valores sociais." (CANDIDO, 1980, p. 20-21)

A natureza dessa relação, como apontada pelo estudioso brasileiro, é essencial para a formalização estética. Assim, não se trata de identificar se um autor específico recebe influência da realidade e se tenta produzir um efeito nos receptores, mas de determinar quais são as influências, em que grau e com qual intenção ele escreve, como se define sua intencionalidade discursiva, seu tom expressivo, novamente recorrendo aos termos de Bakhtin (2003). A obra estética, todavia, é sempre individualizada pela forma e pela atuação do autor-criador, o que exige uma priorização da análise estética, antes da análise da influência do meio. 


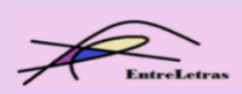

REVISTA ENTRELETRAS (ARAGUAÍNA), V. 12, N. 3, SET./DEZ. 2021 (ISSN 2179-3948 - ONLINE)

A posição do leitor também adquire protagonismo no entendimento da obra literária. A obra só se completa, só adquire acabamento, uma vez que é recebida por um contemplador. Este próprio, assim, se torna parte da obra e, como consciência nela internalizada, configura a construção de sentido que não se efetuaria sem sua presença.

Ainda, pelo menos sociologicamente, segundo Candido (1980), a obra só se completa uma vez que repercute e atua, porque a “[...] arte é um sistema simbólico de comunicação interhumana, e como tal interessa ao sociólogo.” (CANDIDO, 1980, p. 21). O caráter e o grau dessa interação variam de acordo com diversos fatores, como a arte, o estilo e a intencionalidade do autor. Identificar a relação que a obra se propõe a realizar com a sociedade e as intencionalidades do autor mostra-se um momento relevante para a análise do objeto estético.

Essa demonstrada relevância do social, e do extraliterário em geral, para o entendimento do fenômeno literário, também não passa despercebida ao empreendimento autorreflexivo sobre a criação artística que é a obra aqui analisada. O romance expõe explicitamente a relação entre o extraliterário e o mundo da diegese de Julia Marquezim Enone. Por meio da simulação de diversos gêneros discursivos, definidos aqui segundo Bakhtin (2003) e que presumem entonações expressivas variáveis, como notícias de jornais, de revistas ou especulações do narrador a respeito da realidade em que está inserido, a obra, arquitetonicamente acabada, contesta a separação entre o mundo estético e o mundo da vida.

Essa dissolução aparece, muitas vezes, despretensiosamente. Sem anúncio e sem explicação, recortes de jornais que se conectam ao drama vivido pela protagonista do romance de Julia Marquezim Enone confundem a narrativa, trazendo o estético para o mundo da vida ou a vida para o mundo da diegese. Condição inevitável a qualquer objeto estético, essa comparação recíproca, assim como as teorizações precedentes, irrompe na obra, elegendo ao explícito algo que, geralmente, é implícito.

Os limites do estético se encontram em uma determinação “[...] recíproca, tensa e ativa com a realidade valorizada e identificada pelo ato." (BAKHTIN, 2014, p. 30). Essa relação entre o estético e o real ganha complexidade, uma vez que

[...] o panorama é dinâmico, complicando-se pela ação que a obra realizada exerce tanto sobre o público, no momento da criação e na posteridade, quanto sobre o autor, a cuja realidade se incorpora em acréscimo, e cuja fisionomia espiritual se define através dela. (CANDIDO, 1980, p. 74)

No romance de Osman Lins, tais determinações se tornam temas estruturantes a partir da relação que o narrador - solitário, pretenso crítico literário, aspirante a romancista e amante enviuvado - estabelece com a amada através da obra. Ele realiza um movimento do mundo da 


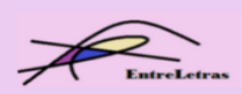

REVISTA ENTRELETRAS (ARAGUAÍNA), V. 12, N. 3, SET./DEZ. 2021 (ISSN 2179-3948 - ONLINE)

vida, dele próprio, para o mundo da vida, de Julia Marquezim Enone, e faz isso por meio do estético. No meio do deslocamento, no entanto, há um processo com o qual ele, conscientemente, lida: a deformação natural a essa passagem, performada pela consciência artisticamente criadora do autor.

O resultado da sua tentativa, surpreendentemente, é paradoxal. No anseio de compreender a consciência criadora e, por consequência, a relação que ela mantém com a pessoa, o narrador tem sua realidade invadida por elementos do objeto estético sobre o qual escreve. Vê, por exemplo, um gato, ou gata, irreal na sua casa, em paralelo à gata Mimosa, também chamada de Memosa, presente no romance. Um dos trechos em que o animal aparece é especialmente significativo da ruptura da realidade experienciada pelo narrador, quando, erguendo os olhos de um livro, vê

[...] sobre o tapete um animal raquítico e sujo, gato ou gata, de perfil, as patas dianteiras estendidas. 'Como a Esfinge!' Que animal era este e como pôde entrar aqui? Esta pergunta foi como incinerada pela combustão do que vi, o intruso era real e, sem deixar de ser real, era a sua invenção, nele coincidiam morte e perenidade, a orla do imaginário ascendia e acercava-se de mim, não só isto, o mundo inteiro apodrecia nesse animal onde reinava o esquecimento e nele começava a nascer outra memória. Devagar, sua escuridão me invade, eu me levanto e, sem saber por que, as mãos como luvas não calçadas, abro os braços, sufocando um grito que não sei se de alegria ou de horror. (LINS, 1976, p. 213, grifos do autor)

Duas referências merecem, aqui, destaque: a Esfinge e o esquecimento. Ambas são associáveis ao romance que ele estuda. A Esfinge, como criatura mítica, é figura extraída da mitologia grega, claramente relacionável a eventos da narrativa de Julia Marquezim Enone, os quais dão nome à obra. $\mathrm{O}$ esquecimento, por sua vez, se associa ao gato da protagonista, que teria recebido o nome, segundo a própria análise do narrador, por uma desfiguração do nome da titã Mnemósina, a Memória. Elementos do livro, portanto, assombram ou encantam o narrador e sua realidade diegética.

Novamente, o movimento de desenredo já havia exposto o que viria a acontecer em seguida. Anteriormente, dois trechos esclarecem a relação entre o narrador, o estético e o extraestético, embora parecessem, formalmente, mais elaborações filosóficas, uma vez que são feitas em terceira pessoa e em tom generalizante, apesar de, claramente, se referirem ao próprio narrador. Notando-se como escritor e diante da fraqueza da sua "realidade", ele sente que o mundo que explora, e a realidade dele, invadem a sua. Cada vez mais, seu propósito de reconhecer no empreendimento ensaístico algo que já acreditava, de certa forma, conhecer, é desvirtuado: sente o mundo explorado prevalecer sobre si. Assim, apesar de todo o conhecimento "culto" que esbanja, lhe parece que um "[...] misterioso processo vem impregnar 


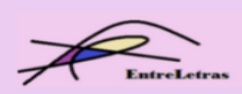

REVISTA ENTRELETRAS (ARAGUAÍNA), V. 12, N. 3, SET./DEZ. 2021 (ISSN 2179-3948 - ONLINE)

o real com o seu discutível símile: e o símile, mais forte que o real, por um momento o reveste." (LINS, 1976, p. 187). Sobrepujado pelo estético, vê-se revestido dele. Ao final, encontra-se imerso na língua da narradora de Julia Marquezim Enone, na sua concepção caótica de tempo e espaço, e na sua (ir)realidade.

Os leitores encontram-se no mesmo problema que o narrador. Diante do objeto estético, encaram um mundo a ser explorado, complexo e que exige profundidade para uma compreensão abrangente. Capazes de alcançar mais facetas da obra, sem a necessária visão do todo arquitetônico bakhtiniano ou sem a perspectiva dialética de Candido (1980), prevaleceria sobre eles o mundo explorado?

\section{Um romance ensaístico, uma autofagia crítica: considerações finais}

O que se vê constituído, no todo arquitetônico do romance de Osman Lins, como as seções anteriores revelaram, é uma obra que a todo momento tenta preencher suas lacunas. A natureza discursiva da literatura demanda a existência de um locutor e um interlocutor e, por vezes, os refigura estruturalmente. Através da sua forma composicional que simula um interlocutor, ao mesmo tempo locutor de um novo enunciado, o discurso em A rainha dos cárceres da Grécia volta-se para si mesmo, problematizando os elementos constituintes da criação verbal e estética.

Para isso, elenca uma série de questionamentos possíveis sobre o ato criador, que é tanto realizado pelo narrador quanto por Julia Marquezim Enone. O discurso artístico, suas teorizações e a relação dialética que o estético mantém com o extraestético são, a todo momento, explicitados e demonstrados como parte estruturantes do objeto estético, novamente, nos romances de Julia Marquezim Enone e no de Osman Lins. A repetição e a reciprocidade das especulações artísticas realizadas pelo narrador dão ambiguidade às suas palavras, que apontam em duas direções: a própria, do sujeito que reflete sobre sua atividade, e a da autora analisada, no juízo crítico. Os aspectos da criação estética, que fundamentam tais postulações, são dispostos e discutidos pelo narrador, a princípio como ferramentas para a compreensão da obra da autora, mas, repetidamente, revelam-se igualmente, ou até mais, capazes de esclarecer problemas referentes ao entendimento do que o narrador escreve.

Esse processo constante figura a atividade do narrador como a busca por uma compreensão da obra. O que ocorre, todavia, é que a procura incessantemente realizada, por vezes em tom condescendente ou na tentativa de tomar controle de um evento singular que lhe causa aflição - a existência de alguém como Julia Marquezim Enone, a relação afetiva que ele 


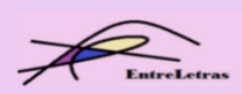

REVISTA ENTRELETRAS (ARAGUAÍNA), V. 12, N. 3, SET./DEZ. 2021 (ISSN 2179-3948 - ONLINE)

desenvolveu com ela e a sua perda -, acaba revelando-se muito mais problemática do que a princípio parecia. O romance que ele estuda ganha complexidade e, mesmo portando um amplo arcabouço de referências literárias, discussões teóricas e conhecimentos sobre a realidade social de Julia Marquezim Enone, com a qual procura paralelos, percebe-se incapaz de alcançar o seu objetivo. Várias hipóteses são levantadas, elencando possíveis soluções estéticas que guiaram a atividade criativa da autora, mas a acumulação de explicações acompanha o crescimento da angústia e do domínio que a obra tem sobre o crítico.

Tal tentativa de compreender o texto e como ele é elaborado, assim como a sua autora, leva o narrador a mergulhar na obra estética. A rainha dos cárceres da Grécia pode ser definida como uma obra dupla, dois romances que exercem influência um sobre o outro. A tentativa do narrador de tomar controle sobre Julia Marquezim Enone e A rainha dos cárceres da Grécia revela-se insuficiente, o romance de primeiro plano é devorado pelo de segundo. O maior exemplo disso, além da progressiva tomada da consciência do narrador de Osman Lins pelo de Julia Marquezim Enone, é a irrupção do insólito no primeiro plano da diegese nos últimos capítulos. Até então, ele era um elemento temático e estruturador apenas da história da protagonista da obra de Julia Marquezim Enone. Quando a ambiguidade entre sobrenatural e loucura irrompe na consciência do narrador de primeiro plano, vê-se a transgressão de níveis operada pela atividade do leitor/crítico que é o narrador de Osman Lins. Nesse momento, ocorre uma construção parecida com a realizada por Cortázar em Continuidad de los Parques, que Gérard Genette (197-, p. 234) chama de metalepse da narrativa, ou seja, uma ruptura dos níveis da narrativa.

O atravessamento de tais planos é subjacente a toda a obra. Ela rompe a hierarquia da diegese e da enunciação constantemente. Sua manifestação mais simples é a anunciada pelo narrador logo no início do texto: tem-se uma personagem, em sua diegese, que analisa uma outra diegese e seu processo criador. Subjacentemente, em um grau mais elevado de quebra dos níveis, esse olhar é autorreflexivo, na medida em que suas constatações por vezes são ambíguas, esclarecem elementos das duas diegeses e dos dois processos criadores. No extremo do atravessamento, ocorre a inversão do processo. O primeiro plano, que discursava sobre o segundo e sobre si mesmo, é invadido pelo objeto da sua visão e vê-se impregnado por ele, incapaz de separar o que lhe é próprio e o que lhe é alheio.

A tentativa do ensaio-romance de dominar Julia Marquezim Enone e sua obra com um discurso autoexplicativo, que não deixa espaço para contestação, vira-se contra o próprio narrador. Ele é consumido física e mentalmente, a ponto de ter que ficar dias de repouso no 


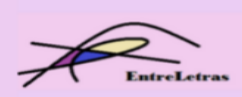

REVISTA ENTRELETRAS (ARAGUAÍNA), V. 12, N. 3, SET./DEZ. 2021 (ISSN 2179-3948 - ONLINE)

escuro pelo agravamento da sua condição ocular. Suas postulações, que pretendiam explicar o romance analisado, acabam funcionando melhor para sua própria obra. Tentando compreender a autora, acaba sendo devorado por si mesmo, pel'A rainha dos cárceres da Grécia e por Julia Marquezim Enone.

\section{Referências bibliográficas}

BAKHTIN, M. Estética da criação verbal. São Paulo: Martins Fontes, 2003.

BAKHTIN, M. Questões de literatura e de estética: a teoria do romance. São Paulo: Hucitec, 2014.

BORGES, J. Kafka y sus precursores. In: BORGES, J. Otras inquisiciones. Obras completas. 1923-1972. Buenos Aires: Eméce, 1974.

BORGES, J. Pierre Menard, autor del Quijote. In: BORGES, J. Ficciones. Madrid: Alianza Editorial, 1997. p. 41-55.

CANDIDO, A. Literatura e sociedade: estudos de teoria e história literária. São Paulo: Ed. Nacional, 1980.

CANDIDO, A. Formação da literatura brasileira: momentos decisivos 1750-1880. São Paulo - Rio de Janeiro: Ouro sobre azul, 2017.

GENETTE, G. Discurso da narrativa: ensaio de método. Lisboa: Vega, 197-.

LINS, O. A rainha dos cárceres da Grécia. São Paulo: Melhoramentos, 1976.

MARTINS, E. O romance e seu direito ao grito: mimesis e representação em A hora da estrela e A rainha dos cárceres de Grécia. 2010. Tese (Doutorado em Letras) - Universidade Federal da Paraíba, João Pessoa, 2010.

NUNES, G. O leitor nas trilhas do texto: um diálogo entre a teoria de Umberto Eco e a poética da leitura de Jorge Luis Borges. 2007. Dissertação (mestrado) - Universidade Estadual Paulista, Instituto de Biociências, Letras e Ciências Exatas, São José do Rio Preto, 2007.

PERRONE-MOISÉS, L. Apresentação. In: TODOROV, T. Estruturas Narrativas. São Paulo: Perspectiva, 2013. p. 9-15. 